\title{
Decreased expression of Sox 7 correlates with the upregulation of the Wnt//-catenin signaling pathway and the poor survival of gastric cancer patients
}

\author{
JIANXIN CUI* , HONGQING XI* , AIZHEN CAI, SHIBO BIAN, BO WEI and LIN CHEN \\ Department of General Surgery, Chinese People's Liberation Army General Hospital, Beijing 100853, P.R. China
}

Received December 15, 2013; Accepted April 15, 2014

DOI: $10.3892 /$ ijmm.2014.1759

\begin{abstract}
Sox7 is a tumor suppressor gene that plays an important role in the inhibition and progression of cancer. In the present study, we sought to investigate Sox7 expression in gastric cancer (GC) and its association with the $\mathrm{Wnt} / \beta$ catenin signaling pathway. We also wished to determine its clinicopathological significance and prognostic implications. Sox7 expression and its effects on the Wnt/ $\beta$-catenin signaling in vitro were assessed by reverse transcription-polymerase chain reaction using the AGS, MKN-45 and GES-1 gastric cell lines. We also used immunohistochemistry on paraffinembedded tissue samples and western blot analysis on fresh tissue samples from patients with GC. The results revealed that Sox7 expression was significantly lower in the GC samples than in distal normal tissues, which was in accordance with our results obtained from our in vitro experiments on the cell lines. However, the expression levels of $\beta$-catenin were significantly higher. Sox 7 and $\beta$-catenin expression significantly correlated with the depth of invasion, lymph node metastasis, distant metastasis and the TNM stage. Patient samples that were Sox7negative correlated with a significantly shorter survival time. Multivariate survival analysis revealed that Sox 7 and $\beta$-catenin had an independent effect on the survival of GC patients. Sox7 and $\beta$-catenin expression in $\mathrm{GC}$ had a negative liner correlation with each other. Our findings suggest that Sox 7 plays an important role in inhibiting tumorigenesis and progression, and may be a potential marker for predicting the prognosis of patients with GC.
\end{abstract}

Correspondence to: Professor Lin Chen or Professor Bo Wei, Department of General Surgery, Chinese People's Liberation Army General Hospital, 28 Fuxing Road, Beijing 100853, P.R. China

E-mail: chenlinbj@sina.com

E-mail: weibobj301@sina.com

*Contributed equally

Key words: gastric cancer, $\beta$-catenin, prognosis, Sox 7 , tumorigenesis

\section{Introduction}

Stomach cancer is one of the common malignancies worldwide and is the second most frequent cause of cancer-related mortality. The ratio of males to females with stomach cancer is approximately 2:1, with the highest incidence of gastric cancer (GC) occurring in East Asia, with approximately 70 cases per 100,000 individuals annually (1). A number of factors have been associated with an increased risk of stomach cancer, including Helicobacter pylori infection, a high consumption of salt-preserved food, smoking and air pollution. Several strategies have been implemented to reduce the severity of GC; however, the final treatment outcomes have not met expectations. At the time of diagnosis of $\mathrm{GC}$, the majority cases already at the advanced stages of tumorigenesis (2).

Damage to the genome alters the expression of proteins that are associated with various essential cellular functions. This results in an enhanced malignancy, particularly in the case of GC. This has been well-known for many years; however, the identification of effective biomarkers for the detection or the targeted therapy of cancer remains incomplete. The sexdetermining region of Y-chromosome (SRY)-related high mobility-group box (Sox) genes belong to the high mobility group (HMG) protein family. These genes encode proteins or transcription factors similar to the SRY gene product from a conserved region (3). Together with Sox 17 and Sox 18, Sox 7 belongs to the Sox F gene subfamily (4). Sox7 was first identified in zebrafish and rats $(5,6)$, with transcriptional regulation carried out through the methylation of a $\mathrm{CpG}$ island at the start site of the gene $(7,8)$. Previous studies have demonstrated that the Sox genes can regulate a number of processes, including gut, B cell, muscle and cardiovascular system development (9-11); they also participate in a number of biological processes in a variety of tumors. The expression of Sox7 has been found to be significantly downregulated in many cancer tissues and cell lines. Sox 7 has also been strongly associated with the $\mathrm{Wnt} / \beta$-catenin signaling pathway, tumor prognosis and the clinicopathological characteristics of cancer $(7,8,12-17)$.

The Wnt $/ \beta$-catenin signaling pathway regulates a variety of cellular process, such as cell fate, proliferation, survival, behavior and migration (18). In this pathway, $\beta$-catenin is a key effector that regulates $\mathrm{Wnt} / \beta$-catenin targets. It is commonly found that the accumulation of $\beta$-catenin leads to 
the aberrant activation of the Wnt/ $\beta$-catenin pathway in human cancers (19-21). However, to date, there are no studies focusing on Sox 7 expression in $\mathrm{GC}$, apart from a few studies investigating the association between Sox 7 expression and the $\mathrm{Wnt} / \beta$-catenin signaling pathway in GC. In the present study, we focused on the association between the molecular pathology of GC and survival. Moreover, we investigated the expression levels of Sox 7 and $\beta$-catenin in GC tissues, normal mucosal tissues and cell lines. We also explored the possible association between Sox 7 and $\beta$-catenin expression levels and clinicopathological characteristics of patients with GC.

\section{Materials and methods}

Patients and specimens. The patients included in our study had been diagnosed with GC and had undergone surgical treatment $(n=258)$ at the General Department of Chinese People's Liberation Army (PLA) General Hospital (Beijing, China) between January 2003 and December 2008. None of the patients had undergone chemotherapy or radiotherapy prior to surgical treatment, nor had they suffered from other synchronous malignancies. Tumors were evaluated by the pathological tumor node metastasis (pTNM) staging system according to the criteria of the American Joint Committee on Cancer (7th edition) and The Japan Gastric Cancer Association (JGCA) guidelines. Data relating to the clinicopathological characteristics of patients and tumors were collected from hospital records. Follow-up data were collected from the database available in our department. The follow-up time began on the day of the primary tumor operation, while the end-point of the overall survival (OS) analysis was the time of death of the patient or our last follow-up session. Paraffin-embedded primary GC specimens from 258 patients were obtained, and 80 distal normal gastric tissues were randomly selected as the normal controls. Another 60 pairs of freshly frozen GC tissue samples and matched normal mucosal tissue samples adjacent to the carcinoma were collected from patients following the above-mentioned criteria. These patients had undergone surgical excision at the General Surgery Department of PLA General Hospital from January 2012 to June 2013; the samples were stored at $-80^{\circ} \mathrm{C}$ until use in western blot analysis. Our study was conducted with the approval of the Chinese PLA General Hospital Research Ethics Committee.

Cell culture. The human GC cell lines, AGS and MKN-45, and the human normal gastric mucosa cell line, GES-1 (obtained from ATCC, Manassas, VA, USA) were cultured in RPMI 1640 medium (Gibco-BRL, Gaithersburg, MD, USA) supplemented with $10 \%$ fetal bovine serum (FBS; Gibco-BRL), $100 \mathrm{U} / \mathrm{ml}$ penicillin and $100 \mu \mathrm{g} / \mathrm{ml}$ streptomycin, at $37^{\circ} \mathrm{C} / 5 \% \mathrm{CO}_{2}$.

Reverse transcription-polymerase chain reaction (RT-PCR). Total RNA was extracted using TRIzol reagent (Invitrogen Life Technologies, Carlsbad, CA, USA) according to a standard proteinase $\mathrm{K}$ method. Reverse transcription to produce cDNA was conducted using a reverse transcription kit (Applied Biosystems, Foster City, CA, USA). We used specific primers and aliquots $(2 \mu \mathrm{l})$ of the cDNA as templates, to amplify fragments of Sox7 (5'-TAAATCAGGGGCCGGGTCG-3' and 5'-CTTCCACGACTTTCCCAGCA-3'), $\beta$-catenin (5'-ATTG
AAGCTGAGGGAGCCAC-3' and 5'-TCCTGGCCATATCC ACCAGA-3') and glyceraldehyde 3-phosphate dehydrogenase (GAPDH; 5'-AGAAGGCTGGGGCTCATTTG-3' and 5'-AGG GGCCATCCACAGTCTTC-3') as an internal control. The thermal cycling conditions we used involved a denaturation step at $95^{\circ} \mathrm{C}$ for $10 \mathrm{~min}$, then 30 cycles at $95^{\circ} \mathrm{C}$ for $30 \mathrm{sec}, 58^{\circ} \mathrm{C}$ for $60 \mathrm{sec}$ and $72^{\circ} \mathrm{C}$ for $30 \mathrm{sec}$, with a final extension step at $72^{\circ} \mathrm{C}$ for $5 \mathrm{~min}$ after the 30 th cycle.

Immunohistochemistry (IHC). Sections (5 $\mu \mathrm{m}$ thick) were cut from paraffin blocks and IHC was conducted using avidin-biotin-peroxidase complex kits (Vector Laboratories, Burlingame, CA, USA), according to the instructions provided by the manufacturer. The sections were subsequently incubated with polyclonal rabbit anti-human Sox7 (1:250 dilution; R\&D Systems, Minneapolis, MN, USA) and polyclonal rabbit anti-human $\beta$-catenin antibodies (1:250; R\&D Systems) at room temperature overnight, in a humidified chamber. Diaminobenzidine (Vector Laboratories) was used as the chromogen and the slides were counterstained with Mayer's hematoxylin. All sections were examined and scored by two independent investigators, who were blinded with regard to the sample groups. We analyzed both the intensity and the extent of positive staining, as previously described $(22,23)$. Intensity was graded as follows: 0 , no staining; 1 , mild intensity; 2 , moderate intensity; 3, severe intensity. The extent of staining was scored as follows: 0 , no positive staining; $1,1-25 \%$ of carcinoma cells was positive; $2,25-50 \%$ was positive; $3,>50 \%$ was positive. The final score for a section was generated by combining the two values for the intensity and extent of staining. A score of $\leq 1$ was considered negative, while a score between 2 and 6 was considered positive.

Protein extraction and western blot analysis. The tissue samples or cells were homogenized in extraction buffer (100 mM Trizma pH 7.5, 10 mM EDTA, 100 mM NaF, 10 mM sodium pyrophosphate, $10 \mathrm{mM}$ sodium orthovanadate, $2 \mathrm{mM}$ phenylmethanesulfonyl fluoride and $0.01 \mathrm{mg} / \mathrm{ml}$ aprotinin) at $4^{\circ} \mathrm{C}$ for $15 \mathrm{~min}$. Following homogenization, Triton X-100 was added to a final concentration of $1 \%(\mathrm{v} / \mathrm{v})$, and the samples were incubated for $30 \mathrm{~min}$ at $4^{\circ} \mathrm{C}$ and then centrifuged $(13,000 \mathrm{x} \mathrm{g}$; $20 \mathrm{~min} ; 4^{\circ} \mathrm{C}$ ). The concentration of total protein in each sample was determined using bovine serum albumin (BSA) as a standard. Equal amounts of protein from each sample were diluted in Laemmli buffer containing dithiothreitol (DTT; $1 \mathrm{M}$ ) and separated by electrophoresis on polyacrylamide gels (SDS-PAGE). The proteins were then transferred onto nitrocellulose membranes, which were blocked with $5 \%$ skim milk. The membranes were incubated at room temperature overnight with the appropriate antibodies [anti-human Sox7 (R\&D Systems), anti-human $\beta$-catenin (R\&D Systems) and anti-human $\beta$-actin (Sigma St. Louis, MO, USA)] diluted in a basal solution containing $3 \%$ skim milk. The membranes were then incubated with the appropriate corresponding secondary antibody $(1: 15,000)$ conjugated to horseradish peroxidase $(\mathrm{HrP})$ at room temperature for $1 \mathrm{~h}$. After a final wash, the signals were visualized using an ECL Western Blotting System kit (GE Healthcare, Little Chalfont, Buckinghamshire, UK). Signals and band intensities were quantified by optical densitometry using ImageJ 1.37 software. 

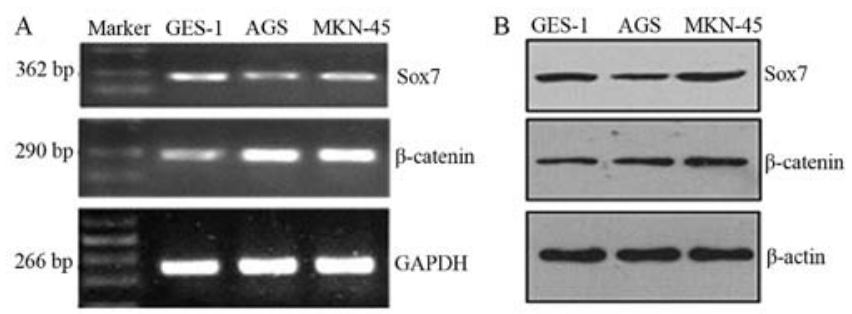

Figure 1. Sox 7 and $\beta$-catenin expression in vitro. (A) RT-PCR analysis revealed that Sox 7 was expressed at lower levels in the AGS and MKN-45 cells gastric cancer compared the GES-1 normal gastric mucosa cells. (B) Western blot analysis revealed that Sox7 was expressed at lower levels in the AGS and MKN-45 levels compared the GES-1 cells.

Statistical analysis. The correlation between various clinicopathological characteristics of the patients with GC and Sox7 gene expression was analyzed using $\chi^{2}$ or Fisher's exact tests. The association between Sox 7 and $\beta$-catenin expression levels was examined using Spearman's rank correlation coefficient or Pearson's correlation coefficient. The paired-samples t-test was used to assess the differences in the relative expression of Sox7 and $\beta$-catenin proteins in GC and normal mucosal tissues. The 5-year OS rate was calculated using the Kaplan-Meier method. The difference between curves was analyzed using the logrank test. Multivariate survival analysis was based on the Cox proportional hazard model. A P-value $<0.05$ was considered to indicate a statistically significant difference. All statistical analyses were performed using SPSS version 17.0 software (SPSS Inc., Chicago, IL, USA).

\section{Results}

Sox7 and $\beta$-catenin expression in the GC cell lines. Sox 7 expression levels were lower in the tumor cell lines compared with the GES-1 cells, whereas $\beta$-catenin was overexpressed in the tumor cell lines (Fig. 1A). The western blot analysis results for the Sox7 and $\beta$-catenin proteins in the cell lines revealed a similar trend (Fig. 1B). The difference in the expression levels was statistically significant $(\mathrm{P}<0.05)$.

IHC analysis of Sox 7 and $\beta$-catenin expression in tissues. Sox7 expression was downregulated to a greater extent in the GC tissues compared with the normal mucosal tissues. Sox 7 protein expression was weak or absent in 119 of the GC samples; in the remaining 139 samples, Sox 7 was mainly
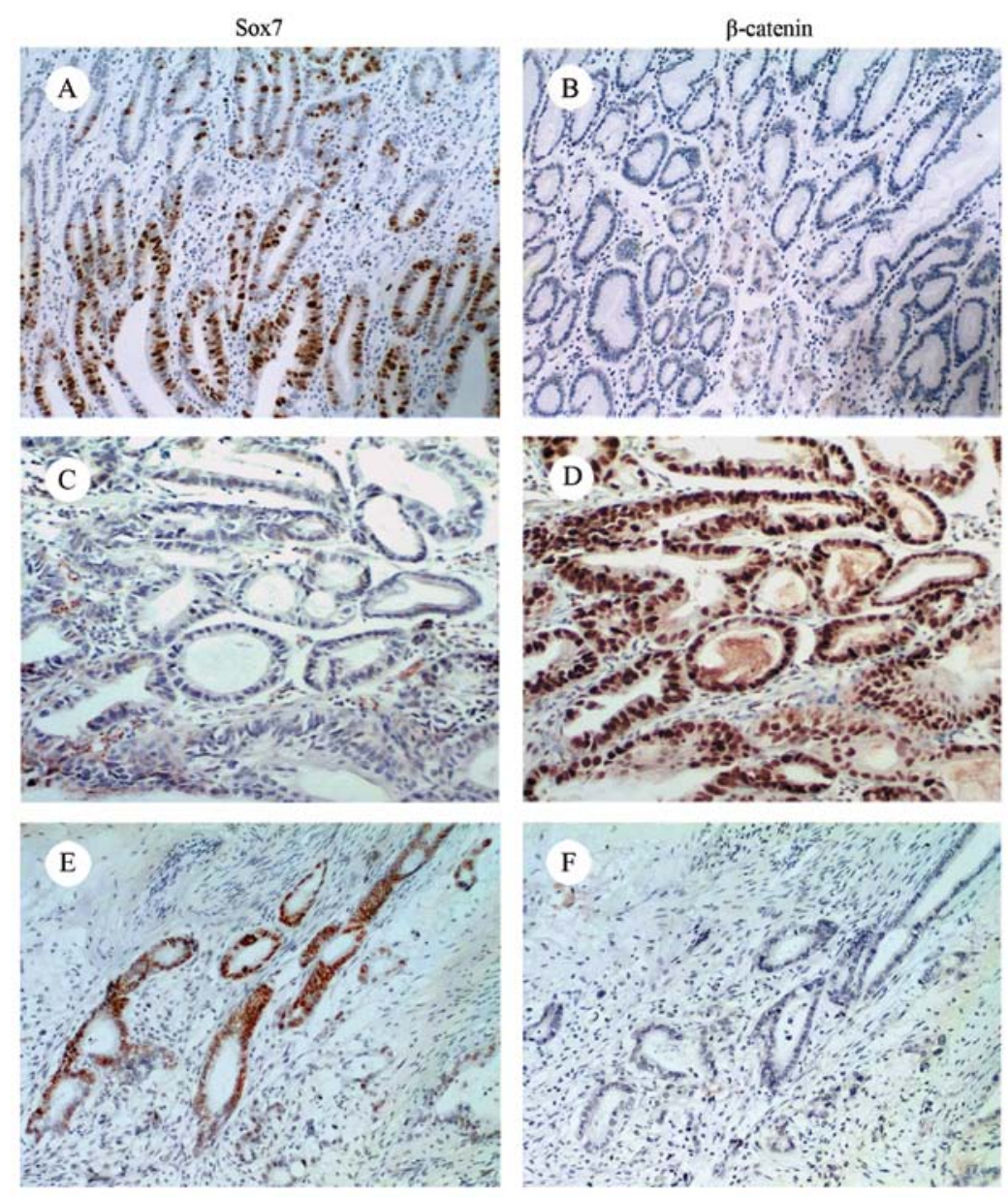

Figure 2. Immunohistochemistry (IHC). Sox7 expression was frequently downregulated and correlated with $\beta$-catenin expression in the gastric cancer (GC) samples. Sox 7 was expressed mainly in the nucleus, and to a lesser extent in the cytoplasm. $\beta$-catenin was present in the nucleus, cytoplasm and cell membrane. (A) Sox7 was expressed mainly in the nucleus, and in the cytoplasm to a lesser extent, of distal normal gastric mucosal tissue samples (magnification, x100); (B) $\beta$-catenin expression was absent in distal normal gastric mucosal tissue samples (x100); (C and D) Sox7 was weakly expressed at sites where $\beta$-catenin expression was significantly upregulated in GC (x100); (E and F) Sox7 expression was upregulated at sites where $\beta$-catenin expression was absent in GC samples (x100). 
Table I. Association of Sox 7 and $\beta$-catenin expression with clinicopathological characteristics of gastric cancer patients.

\begin{tabular}{|c|c|c|c|c|c|c|}
\hline \multirow[b]{2}{*}{ Variables } & \multicolumn{3}{|c|}{ Sox7 } & \multicolumn{3}{|c|}{$\beta$-catenin } \\
\hline & Positive & Negative & P-value & Positive & Negative & P-value \\
\hline \multicolumn{7}{|l|}{ Gender } \\
\hline Male & 71 & 80 & 0.488 & 82 & 69 & 0.645 \\
\hline Female & 55 & 52 & & 55 & 52 & \\
\hline \multicolumn{7}{|l|}{ Age, years } \\
\hline$\leq 45$ & 31 & 33 & 0.286 & 33 & 31 & 0.921 \\
\hline $45-60$ & 53 & 44 & & 51 & 46 & \\
\hline$>60$ & 42 & 55 & & 53 & 44 & \\
\hline \multicolumn{7}{|l|}{ Tumor site } \\
\hline Upper & 34 & 39 & 0.651 & 42 & 31 & 0.594 \\
\hline Middle & 45 & 40 & & 42 & 43 & \\
\hline Low & 47 & 53 & & 53 & 47 & \\
\hline \multicolumn{7}{|l|}{ Tumor size } \\
\hline$\leq 4 \mathrm{~cm}$ & 52 & 52 & 0.759 & 51 & 53 & 0283 \\
\hline$>4 \mathrm{~cm}$ & 74 & 80 & & 86 & 68 & \\
\hline \multicolumn{7}{|c|}{ Lauren classification } \\
\hline Intestinal & 94 & 101 & 0.672 & 102 & 93 & 0.555 \\
\hline Diffuse & 23 & 25 & & 25 & 23 & \\
\hline Mixed & 9 & 6 & & 10 & 5 & \\
\hline \multicolumn{7}{|l|}{ Histological type } \\
\hline Adenocarcinoma & 102 & 114 & 0.239 & 115 & 101 & 0.919 \\
\hline Other & 24 & 18 & & 22 & 20 & \\
\hline \multicolumn{7}{|c|}{ Differentiation grade } \\
\hline Well-Moderate & 74 & 90 & 0.115 & 101 & 63 & 0.001 \\
\hline Poor & 52 & 42 & & 36 & 58 & \\
\hline \multicolumn{7}{|l|}{ Depth of invasion } \\
\hline $\mathrm{T} 1$ & 22 & 7 & 0.001 & 5 & 24 & 0.001 \\
\hline $\mathrm{T} 2$ & 38 & 33 & & 31 & 40 & \\
\hline T3 & 53 & 58 & & 67 & 44 & \\
\hline $\mathrm{T} 4$ & 13 & 34 & & 34 & 13 & \\
\hline \multicolumn{7}{|c|}{ Lymph node metastasis } \\
\hline No & 52 & 22 & 0.001 & 27 & 47 & 0.004 \\
\hline N1 & 43 & 55 & & 54 & 44 & \\
\hline $\mathrm{N} 2$ & 26 & 40 & & 42 & 24 & \\
\hline N3 & 5 & 15 & & 14 & 6 & \\
\hline \multicolumn{7}{|l|}{ Distant metastasis } \\
\hline M0 & 120 & 118 & 0.079 & 121 & 117 & 0.012 \\
\hline M1 & 6 & 14 & & 16 & 4 & \\
\hline \multicolumn{7}{|l|}{ TNM stage } \\
\hline I & 36 & 10 & 0.001 & 7 & 39 & 0.001 \\
\hline II & 63 & 70 & & 76 & 57 & \\
\hline III & 22 & 39 & & 39 & 22 & \\
\hline IV & 5 & 13 & & 15 & 3 & \\
\hline
\end{tabular}

A value of $\mathrm{P}<0.05$ was considered to indicate a statistically significant difference.

expressed in the nucleus, and, to a lesser extent, in the cytoplasm. The prevalence of Sox7 expression was $86.3 \%$ (69/80) in the distal normal mucosa samples, that is to say, much higher than that in the cancerous tissue samples. Staining 
Table II. Correlation between Sox 7 and $\beta$-catenin expression in gastric cancer.

\begin{tabular}{|c|c|c|c|c|c|c|}
\hline \multirow[b]{2}{*}{$\beta$-catenin } & \multicolumn{2}{|c|}{ Sox7 } & \multicolumn{2}{|c|}{$\chi^{2}$ test } & \multicolumn{2}{|c|}{ Correlation analysis } \\
\hline & + & - & $\chi^{2}$ & P-value & $\mathrm{R}$ & P-vlaue \\
\hline+ & 22 & 115 & 125.614 & 0.001 & -0.698 & 0.001 \\
\hline- & 104 & 17 & & & & \\
\hline
\end{tabular}

$\mathrm{R}$, correlation coefficient. A value of $\mathrm{P}<0.05$ was considered to indicate a statistically significant difference.
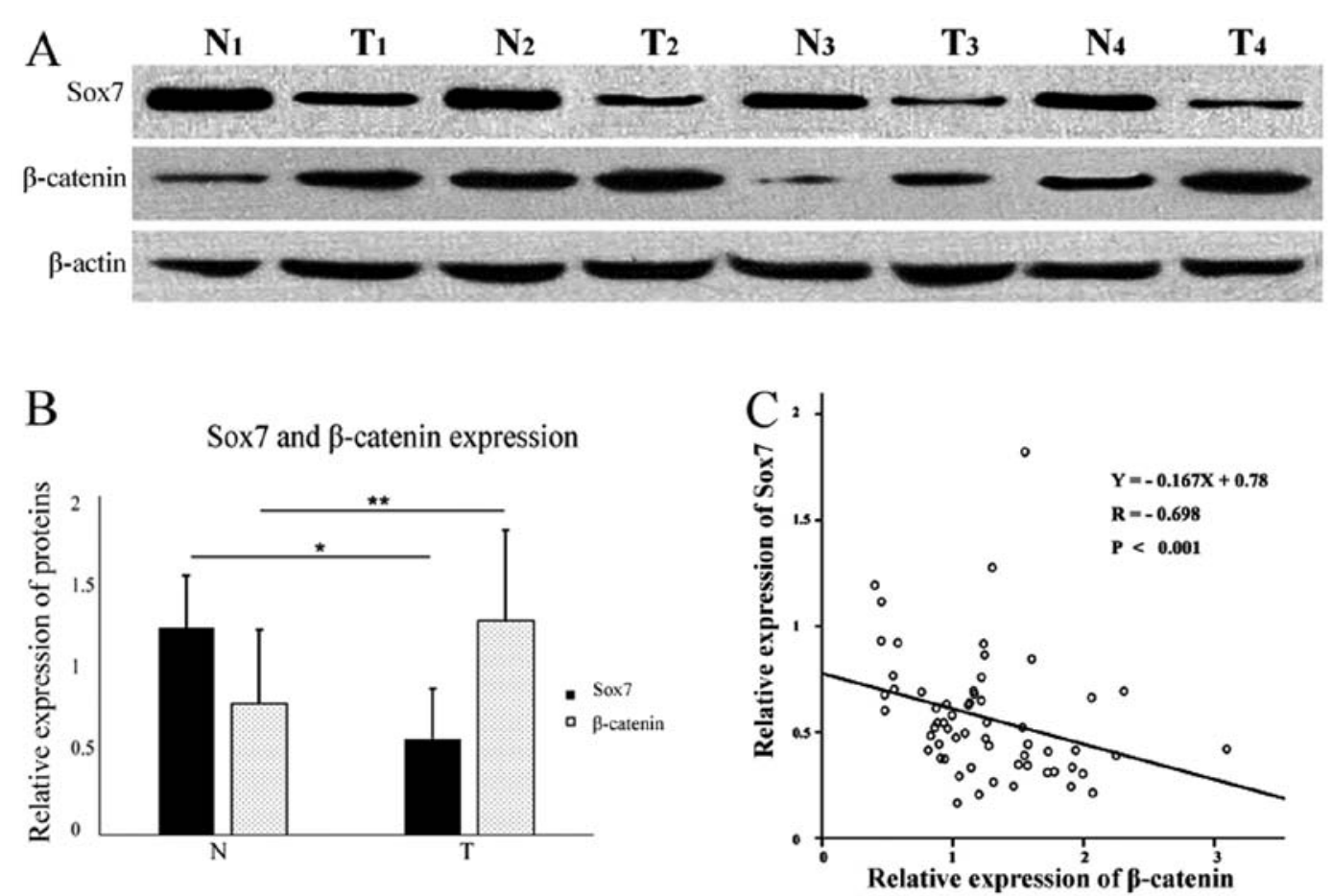

Figure 3. Western blot analysis of Sox7 expression in fresh-frozen tissues and its correlation with $\beta$-catenin expression levels. (A) Western blot analysis revealed that Sox 7 was upregulated in the normal tissue samples, and that Sox7 suppressed the expression of $\beta$-catenin in normal tissue samples. (B) Sox7 and $\beta$-catenin expression levels were significantly different between the two groups $\left({ }^{* * * *} \mathrm{P}<0.05\right)$. (C) Correlation between Sox7 and $\beta$-catenin relative expression levels in gastric cancer. Protein levels were relative to $\beta$-actin. There was a significant negative linear correlation between Sox7 and $\beta$-catenin protein expression $(\mathrm{P}<0.001$, $\mathrm{R}=-0.698)$. $\mathrm{N}$, normal samples; $\mathrm{T}$, tumor samples.

was mainly observed in the nucleus or cytoplasm (Fig. 2A and $\mathrm{C}$ ). By contrast, $\beta$-catenin was overexpressed in the GC tissues (137/258) and weakly expressed or absent in the normal mucosa (56/80) (Fig. 2B and D). $\beta$-catenin was observed in the nucleus, cytoplasm and cellular membrane. At sites where Sox7 was expressed, $\beta$-catenin was weakly expressed or absent and, where $\beta$-catenin was expressed, Sox 7 was absent (Fig. 2C-F).

Significant positive associations were observed between Sox7 expression and the differentiation grade $(\mathrm{P}=0.001)$, depth of invasion $(\mathrm{P}=0.001)$, lymph node metastasis $(\mathrm{P}=0.001)$ and pTNM stage $(\mathrm{P}=0.001$; Table I). The expression of $\beta$-catenin showed a significant correlation with the differentiation grade $(\mathrm{P}=0.001)$, depth of invasion $(\mathrm{P}=0.001)$, lymph node metastasis $(\mathrm{P}=0.004)$, distant metastasis $(\mathrm{P}=0.012)$ and $\mathrm{pTNM}$ stage $(\mathrm{P}=0.001$; Table I). There was a significant association between the downregulated Sox 7 expression and the high-level $\beta$-catenin expression $(\mathrm{P}=0.001$; Table II). An analysis of the association between Sox 7 and $\beta$-catenin expression by IHC revealed a significant negative correlation $(\mathrm{R}=-0.698, \mathrm{P}=0.001$; Table II $)$.

Western blot analysis of Sox 7 and $\beta$-catenin expression in tissue samples. Sox 7 protein expression was detected in 29 tumor and 58 normal mucosal tissue specimens (Fig. 3A). The mean relative expression level of Sox 7 was $0.57 \pm 0.29$ in the tumor samples and $1.23 \pm 0.31$ in the normal samples (Fig. 3B). $\beta$-catenin protein expression was detected in $94.7 \%(56 / 60)$ of the tumor specimens and in $66.7 \%(40 / 60)$ of the normal mucosal tissue samples (Fig. 3A). The mean relative expression levels of $\beta$-catenin were $1.25 \pm 0.53$ in the tumor samples, and $0.77 \pm 0.43$ in the normal mucosal tissues (Fig. 3B). The relative expression level of Sox 7 protein in the tumor samples was significantly lower $(\mathrm{P}<0.05)$ than that in the matched distal normal mucosal tissues, whereas $\beta$-catenin expression was significantly higher $(\mathrm{P}<0.05$; Fig. $3 \mathrm{~B})$. 
Table III. Cox regression analysis of prognostic factors in gastric cancer.

95\% CI for HR

\begin{tabular}{lccccccr}
\cline { 5 - 7 } Prognostic variables & $\mathrm{B}$ & $\mathrm{SE}$ & Wald test & P-value & HR & Lower & Upper \\
\hline Gender & -0.166 & 0.168 & 0.979 & 0.322 & 0.847 & 0.609 & 1.177 \\
Age & 0.126 & 0.106 & 1.432 & 0.231 & 1.135 & 0.923 & 1.396 \\
Tumor site & -0.115 & 0.099 & 1.360 & 0.243 & 0.891 & 0.734 & 1.082 \\
Tumor size & -0.167 & 0.170 & 0.965 & 0.326 & 0.846 & 0.607 & 1.180 \\
Lauren classification & 0.384 & 0.173 & 4.931 & 0.026 & 1.469 & 1.046 & 2.061 \\
Histology type & -0.334 & 0.279 & 1.429 & 0.232 & 0.716 & 0.414 & 1.238 \\
Differentiation grade & -0.095 & 0.194 & 0.241 & 0.623 & 0.909 & 0.622 & 1.329 \\
Depth of invasion & 0.250 & 0.143 & 3.059 & 0.080 & 1.284 & 0.970 & 1.698 \\
Lymph node metastasis & 0.365 & 0.155 & 5.541 & 0.019 & 1.441 & 1.063 & 1.953 \\
Distant metastasis & 0.173 & 0.367 & 0.222 & 0.638 & 1.189 & 0.579 & 2.440 \\
TNM stage & 0.536 & 0.253 & 4.486 & 0.034 & 1.709 & 1.041 & 2.805 \\
Sox7 expression & -0.404 & 0.205 & 3.888 & 0.049 & 0.668 & 0.447 & 0.998 \\
$\beta$-catenin expression & 0.442 & 0.211 & 4.395 & 0.036 & 1.556 & 1.029 & 2.352 \\
\hline
\end{tabular}

$\mathrm{B}$, partial regression coefficient; $\mathrm{CI}$, confidence interval; HR, hazard ratio; SE, standard error; Wald value statistic for $(\mathrm{B} / \mathrm{SE}) 2$; $\mathrm{P}<0.05$, statistically significant.

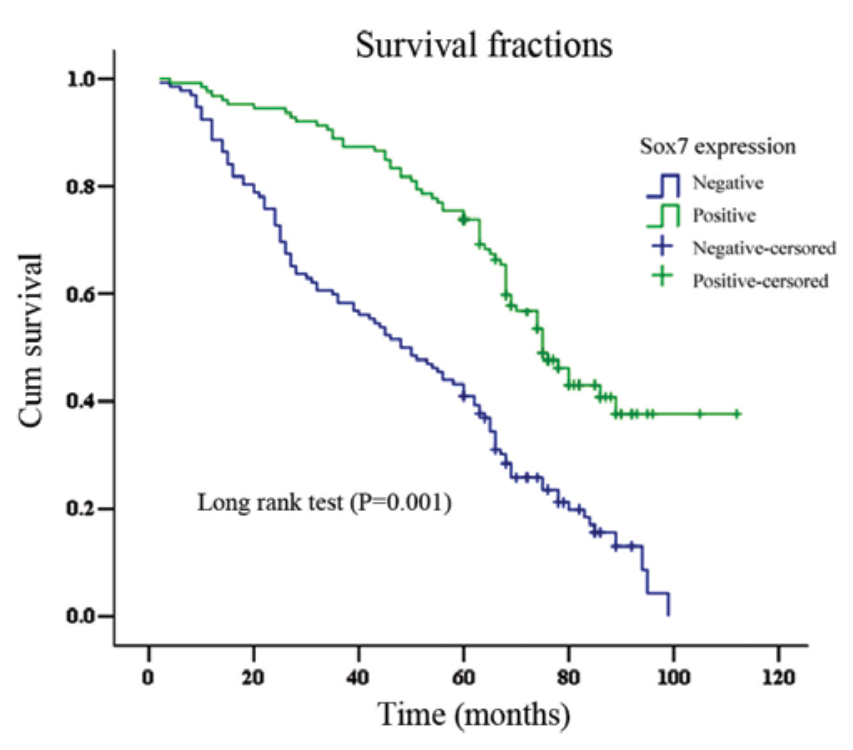

Figure 4. Kaplan-Meier survival analysis of Sox7 status $(n=256)$. The blue line indicates Sox7-negative patients. The green line indicates Sox7-positive patients with GC $(\log -\mathrm{rank}=35.99, \mathrm{P}=0.001)$.

Association between Sox7 and $\beta$-catenin expression. IHC staining revealed a correlation between Sox 7 and $\beta$-catenin expression. We conducted a linear regression analysis of our western blot analysis results and found a negative correlation between the relative expression levels of Sox7 and $\beta$-catenin protein in the GC samples ( $\mathrm{Y}=-0.167 \mathrm{X}+0.78, \mathrm{P}<0.001$; Fig. 3C).

Survival analysis. The OS time for patients that were Sox7-negative was significantly shorter (mean, $49.7 \pm 2.6$ months) than that for Sox7-positive cases $(78.5 \pm 3.0$ months; log-rank test, $\mathrm{P}<0.001$; Fig. 4). The overall 5-year survival rate for the Sox7-negative group $(40.9 \%)$ was lower than that of the Sox7-positive group (69.2\%; log-rank $=35.99, \mathrm{P}=0.001)$. Sox7 expression was found to be an independent prognostic factor $(\mathrm{P}=0.001)$ by the Cox proportional hazard model. Other independent prognostic factors were the Lauren classification, lymph node metastasis, pTNM stage and $\beta$-catenin expression (all $\mathrm{P}<0.05$; Table III).

\section{Discussion}

In order to develop sensitive and specific therapies against GC, molecular biomarkers must be determined (24). Abnormal expression levels of members of the Sox gene family usually correlate with malignant and metastatic tumors $(16,25)$. Based on our findings, we suggest that Sox 7 plays an important role in the inhibition of carcinogenesis and the progression of GC. The results from a previous study demonstrated that Sox 7 mRNA levels were increased in the MKN-45 cell line (13). In the present study, we found that Sox7 expression was decreased in the GC cell lines. Our findings were confirmed by IHC analyses of GC tissues, suggesting that normal expression levels of Sox7 play an important role in suppressing carcinogenesis. Similar results have been reported for prostate, colorectal, endometrial, lung and breast cancer $(7,8,14,16,17)$. In our study, Sox7 expression negatively correlated with the depth of invasion, lymph node metastasis, distant metastasis and pTNM stage. These findings suggest that Sox7 expression levels are associated with the malignancy of GC and possibly play a potential role in predicting the progression of GC.

Previous findings have suggested that Sox genes are widespread and play potential roles in regulating the Wnt/ $\beta$ catenin signaling pathway during development (26). A number of studies have demonstrated that the $\mathrm{Wnt} / \beta$-catenin pathway, in which $\beta$-catenin is a key regulator, is involved in the carcinogenesis, progression and prognosis of a variety of 
malignancies, $\mathrm{GC}$ in particular (27-30). Mutations in $\beta$-catenin are involved in regulating the occurrence of tumors. Our results demonstrate that $\beta$-catenin is often present in GC tissues, positively correlating with the differentiation grade, depth of invasion, lymph node metastasis, distant metastasis and pTNM stage. These findings further indicate that the Wnt/ $\beta$-catenin pathway plays an important role in the progression of GC.

A motif in the Sox7 protein enables it to bind to $\beta$-catenin, enabling their interaction (31). Previous studies have indicated that the regulation of the Wnt/ $\beta$-catenin signaling pathway by Sox7 results in the disruption of the transcriptional functions of the $\beta$-catenin/TCF/LEF-1 complex (12). Sox7 has been reported to be an independent checkpoint for $\beta$-catenin function in prostate and colon epithelial cells (8). In this study, we investigated the association between Sox 7 and $\beta$-catenin using IHC. $\beta$-catenin was present in the majority of Sox7-negative tissues; at most Sox7-positive sites, $\beta$-catenin was absent. We speculated that there was a negative correlation between Sox7 and $\beta$-catenin, which was confirmed by the linear regression analysis of our western blot analysis results. We therefore suggest that the interaction between Sox 7 and $\beta$-catenin plays an important role in carcinogenesis and the progression of GC. Previous research suggests that the methylation of a $\mathrm{CpG}$ island plays a major role as a transcriptional regulator of the Sox 7 gene $(8,16,32)$; therefore, we hypothesized that the regulation of $\beta$-catenin signaling by targeting or upregulating Sox7 expression may prevent carcinogenesis and control the progression of GC (33).

Previous similar studies have demonstrated that the expression of Sox7 in lung and prostate cancer is associated with the prognosis or survival of patients $(16,17,32)$. In our study, Kaplan-Meier survival analysis suggested that the reduced expression of the Sox7 gene was associated with the poor prognosis of GC patients. Sox7-negative GC patients showed a significantly shorter OS compared with Sox7-positive patients, suggesting that the downregulated expression of Sox 7 contributes to the malignancy of the tumor. It may also play a role as a potential biomarker for identifying GC cases with a poor prognosis.

In conclusion, our data demonstrate that the expression of Sox7 is lower in GC cell lines compared with their normal counterparts. We found that Sox7 expression levels in human tissues were similar to those observed in GC tissues, while the opposite was observed for $\beta$-catenin levels. We also observed a negative correlation between Sox 7 and $\beta$-catenin expression levels, indicating that Sox 7 is possibly associated with the Wnt/ $\beta$-catenin signaling pathway. Sox7 may be a potential indicator for predicting the clinical outcome of GC patients. We believe that our findings can significantly contribute to our understanding of the molecular mechanisms of GC carcinogenesis and progression.

\section{Acknowledgements}

This study was supported by grants from the National Nature Science Foundation of China (nos. 81272698, 81101883 and 81172368), a grant from the PLA Medical Technology Key Project of Scientific Research in the 12th Five-Year-Plan (no. BWS12J049), a grant from PLA medical and health research fund project (no. 11BJZ17), a grant from the Capital Health
Research and Development of Special (no. 2011-5001-01), and a grant from the Major Science and Technology Project of 'National Significant New Drug Creation' from the Major Science and Technology of China (no. 2011ZX09307-001-05).

\section{References}

1. Jemal A, Bray F, Center MM, Ferlay J, Ward E and Forman D: Global cancer statistics. CA Cancer J Clin 61: 69-90, 2011.

2. Hartgrink HH, Jansen EP, van Grieken NC and van de Velde CJ: Gastric cancer. Lancet 374: 477-490, 2009.

3. Bowles J, Schepers G and Koopman P: Phylogeny of the SOX family of developmental transcription factors based on sequence and structural indicators. Dev Biol 227: 239-255, 2000.

4. Chew LJ and Gallo V: The Yin and Yang of Sox proteins: Activation and repression in development and disease. J Neurosci Res 87: 3277-3287, 2009.

5. Shiozawa M, Hiraoka Y, Komatsu N, Ogawa M, Sakai Y and Aiso S: Cloning and characterization of Xenopus laevis xSox7 cDNA. Biochim Biophys Acta 1309: 73-76, 1996.

6. Taniguchi K, Hiraoka Y, Ogawa M, Sakai Y, Kido S and Aiso S: Isolation and characterization of a mouse SRY-related cDNA, mSox7. Biochim Biophys Acta 1445: 225-231, 1999.

7. Stovall DB, Wan M, Miller LD, et al: The regulation of SOX7 and its tumor suppressive role in breast cancer. Am J Pathol 183: $1645-1653,2013$.

8. Guo L, Zhong D, Lau S, et al: Sox7 is an independent checkpoint for beta-catenin function in prostate and colon epithelial cells. Mol Cancer Res 6: 1421-1430, 2008.

9. Endo Y, Deonauth K, Prahalad P, Hoxter B, Zhu Y and Byers SW: Role of Sox-9, ER81 and VE-cadherin in retinoic acid-mediated trans-differentiation of breast cancer cells. PLoS One 3: e2714, 2008.

10. Gandillet A, Serrano AG, Pearson S, Lie ALM, Lacaud G and Kouskoff V: Sox7-sustained expression alters the balance between proliferation and differentiation of hematopoietic progenitors at the onset of blood specification. Blood 114: 4813-4822, 2009.

11. Kamachi Y and Kondoh H: Sox proteins: regulators of cell fate specification and differentiation. Development 140: 4129-4144, 2013.

12. Chan DW, Mak CS, Leung TH, Chan KK and Ngan HY: Down-regulation of Sox7 is associated with aberrant activation of Wnt/b-catenin signaling in endometrial cancer. Oncotarget 3: 1546-1556, 2012.

13. Katoh M: Expression of human SOX7 in normal tissues and tumors. Int J Mol Med 9: 363-368, 2002.

14. Hayano T, Garg M, Yin D, et al: SOX7 is down-regulated in lung cancer. J Exp Clin Cancer Res 32: 17, 2013.

15. Futaki S, Hayashi Y, Emoto T, Weber CN and Sekiguchi K: Sox7 plays crucial roles in parietal endoderm differentiation in F9 embryonal carcinoma cells through regulating Gata-4 and Gata-6 expression. Mol Cell Biol 24: 10492-10503, 2004.

16. Zhang Y, Huang S, Dong W, et al: SOX7, down-regulated in colorectal cancer, induces apoptosis and inhibits proliferation of colorectal cancer cells. Cancer Lett 277: 29-37, 2009.

17. Zhong WD, Qin GQ, Dai QS, et al: SOXs in human prostate cancer: implication as progression and prognosis factors. BMC Cancer 12: 248, 2012.

18. Logan CY and Nusse R: The Wnt signaling pathway in development and disease. Annu Rev Cell Dev Biol 20: 781-810, 2004.

19. Karim R, Tse G, Putti T, Scolyer R and Lee S: The significance of the Wnt pathway in the pathology of human cancers. Pathology 36: 120-128, 2004.

20. Polakis P: Wnt signaling in cancer. Cold Spring Harb Perspect Biol 4: 2012.

21. Kolligs FT, Bommer G and Goke B: Wnt/beta-catenin/tcf signaling: a critical pathway in gastrointestinal tumorigenesis. Digestion 66: 131-144, 2002 .

22. Zhao P, Li Y and Lu Y: Aberrant expression of CD133 protein correlates with $\mathrm{Ki}-67$ expression and is a prognostic marker in gastric adenocarcinoma. BMC Cancer 10: 218, 2010.

23. Xi HQ and Zhao P: Clinicopathological significance and prognostic value of EphA3 and CD133 expression in colorectal carcinoma. J Clin Pathol 64: 498-503, 2011.

24. Filomena A, Saieva C, Lucchetti V, et al: Gastric cancer surveillance in a high-risk population in tuscany (Central Italy): preliminary results. Digestion 84: 70-77, 2011. 
25. Wegner M: From head to toes: the multiple facets of Sox proteins Nucleic Acids Res 27: 1409-1420, 1999.

26. Kormish JD, Sinner D and Zorn AM: Interactions between SOX factors and Wnt/beta-catenin signaling in development and disease. Dev Dyn 239: 56-68, 2010.

27. Willert K and Nusse R: Beta-catenin: a key mediator of Wnt signaling. Curr Opin Genet Dev 8: 95-102, 1998.

28. Wu WK, Cho CH, Lee CW, et al: Dysregulation of cellular signaling in gastric cancer. Cancer Lett 295: 144-153, 2010.

29. Chan DW, Chan CY, Yam JW, Ching YP and Ng IO: Prickle-1 negatively regulates Wnt/beta-catenin pathway by promoting Dishevelled ubiquitination/degradation in liver cancer. Gastroenterology 131: 1218-1227, 2006.
30. Qi J and Zhu YQ: Targeting the most upstream site of Wnt signaling pathway provides a strategic advantage for therapy in colorectal cancer. Curr Drug Targets 9: 548-557, 2008.

31. Takash W, Canizares J, Bonneaud N, et al: SOX7 transcription factor: sequence, chromosomal localisation, expression, transactivation and interference with Wnt signalling. Nucleic Acids Res 29: 4274-4283, 2001.

32. Li B, Ge Z, Song S, et al: Decreased expression of SOX7 is correlated with poor prognosis in lung adenocarcinoma patients. Pathol Oncol Res 18: 1039-1045, 2012.

33. Castillo SD and Sanchez-Cespedes M: The SOX family of genes in cancer development: biological relevance and opportunities for therapy. Expert Opin Ther Targets 16: 903-919, 2012. 